\title{
Minireview
}

\section{The important role of matrix metalloproteinases in nematode parasites}

\author{
M. AZAMI ${ }^{1}$, M. ANVARINEJAD ${ }^{2 *}$, M. JAMSHIDIAN GHALESEFIDI ${ }^{3}$ \\ ${ }^{1}$ Skin Diseases and Leishmaniasis Research Center, Isfahan University of Medical Scienco Isfahan, Iran; \\ ${ }^{2}$ Professor Alborzi Clinical Microbiology Research Center, Nemazee Teaching Hospit Schou $\mathrm{f}$ Medicin \\ Shiraz University of Medical Sciences, Shiraz, Iran, E-mail: anvarineja \\ ${ }^{3}$ Moddares Hospital, Isfahan University of Medical Sciences, I

\section{Introducti}

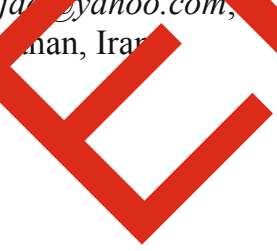

\section{Summary}

Matrix metalloproteinases (MMPs) represent a large family of over twenty different secreted or membrane-bound endopeptidases, involved in many physiological (embryogenesis, precursor or stem cell mobilization, tissue remodeling during wound healing, etc.), as well as pathological (inflammation, tumor progression and metastasis in cancer, vascular pathology, etc.) conditions. For a long MMPs were considered only for the ability to de ade extracellular matrix (ECM) molecules (e.g., colla laminin, fibronectin) and to release hidde opes fr the ECM. However, expressions of man MMPs ave bee associated with several pathological $c$ ditions. has been established that the MMPs are cons ed th animal kingdom and studies $o^{f}$ iverte have demonstrated that primarily they involved in arious developing functions in hyd $D$. ophila, sea chin and nematodes. The syntheses of th proteolytic enzymes and their release as cretory and se tory products have been reported in arious parasitic nem odes. Host invasion and tissu nigration several nematodes have been linked to the $a$ resc 1 and release of parasite-derived proteases numingitors suggest that the enzyp may a m lop ceinase. Moreover, substrate im gnated mograph analysis of extracts and excreto and se parasites have ared the multiple enzyme activities of MMPs with vâ us molecular weights. More research on MMP degradomo nematode parasites can provide valuable information ror intense evaluation of pathogenesis caused by these parasites.

Keywords: matrix metalloproteinase; endopeptidases; nematode parasites
Matrix metalloproten do $111 \mathrm{a} 2^{+}$-dependen nd $\mathrm{Zn} 2^{+}$-containing endopepties, strictly related, which can degrade almost all comnents of the tracellular matrix (ECM), but also non$n$ rix proteins isse \& Nagase, 2003). It has been establis that var as biological processes including cell migration, nd healing, tissue differentiation, immune tem have been accomplished by morphological changes n exw Cellular matrix (Parks \& Shapiro, 2000).

MMPs are the major group of enzymes with ability for degrading extra cellular matrix proteins and this process of ECM remodeling is responsible for all these necessary processes (Shapiro, 1998). These proteins may be found from bacteria to advanced forms of life even in several viruses and have been considered as a group of highly conserved proteins throughout the course of evolution (Clark, 2001).

These enzymes seem to play various functional roles and touch many aspects of physiological and pathological processes not only in vertebrates but also in invertebrates (Mannello et al., 2005). The parasitic nematodes are the major group of invertebrates, which dwell in different organs of vertebrate hosts (Anderson \& Anderson, 2000). Many of these parasites to complete their life cycle have to migrate or invade through various organs of their hosts. During this journey, expression and release of MMPs by various parasitic nematodes have been associated with the pathology resulting from histolysis (Williamson et al., 2006). Genetic analysis and cDNA cloning of MMPs have been evaluated in few parasitic nematodes (Salter et al., 2002; Uparanukraw et al., 2001; Wang et al., 2001).

The aim of this review is to focus the attention the role played by MMPs in the pathogenesis process that caused by nematode parasites. 


\section{MMPs and nematode parasites}

Metalloproteinases comprise a heterogeneous group of proteolytic enzymes whose main characteristic is the utilization of a metal ion to polarize a water molecule and perform hydrolytic reactions. MMPs are a major group of zinc-dependent endopepdidases with a ability to cleave one or more extracellular matrix constituents as well as nonmatrix proteins (Williamson et al., 2006). These enzymes include a wide range of proteases in many organisms and play essential roles in multiple biological processes. By virtue of these proteolytic property proteases regulate a variety of cellular processes such as cell proliferation, cellcycle progression, tissue differentiation and migration, apoptosis, senescence, DNA replication and autophagy (Yoshizaki et al., 2002). In metazoans, proteolytic activities are also involved in the maintenance of tissue homeostasis and in the regulation of different physiological processes such as fertilization and fecundation, embryonic development, wound healing, tissue remodeling, immune response and angiogenesis (Ugalde et al., 2010). However, expressions of some of the MMPs have been associated with different pathological manifestations, which are predominantly associated with inflammation, arthritis, cancer metastasis and parasitic invasion through host's tissues (Aggarwal et al., 2006; McDonnell et al., 1992; Ugalde et al., 2010). MMPs can be categorized as collagenases, gelatinases, elastases, stromelysins, matrilysins, and $\mathrm{m}$ brane-type MMPs based on their substrate specificity a their amino acid sequence similarity (Hijova, 2005; Naga et al., 2006).

Life cycles of many nematode parasites ce of of fferent migratory as well as invasive larval ses in $h$ environment, even sometimes young and ad may in their nature (Lai et al., 2005b) ost in and tissue migration of several nematod have been ked to the expression and release of aras derived pro ses. In nematodes, MMPs are the proteases hich are thought to play an important and sential role in se migratory and invasive phenomen Babu, 2012). Nemat de MMPs generally include agenas gelatinases and elastases (Healer et al., 199 Mar va et al. 1998).

Most of reches uated $\mathrm{P}$ from excretory and secretor prod $\mathrm{s}$ as $\mathrm{w}$ as extracts of parasites (Lai et al 2005b). itial pern of MMPs research in nematode nclude and measurement of activity in differe, stages or nematode parasites. Researchers determine collagenilytic activity in extracts of adult worms, in hicrofilariae of Onchocerca volvulus and in live infective larvae and adult female worms of Brugi malayi (Petralanda et al., 1986). In culture, infective larvae of $B$. malayi also secreted large amounts of collagenase. Studies with enzyme inhibitors, antigen-antibody reactions and immunoprecipitation indicated that this protease might be a metalloproteinase. In another study scientists did characterize this metalloproteinase in Toxocara canis by using different techniques (Lai et al., 2005a).

Various forms of enzyme have been determined by zy- mography where they found two bands with molecular weights of 120 and $32 \mathrm{kDs}$. This group has optimum activity at $\mathrm{pH} 9$ with less activity at $\mathrm{pH} 5$ and 7. As a potent inhibitor Phenylmethylsulfonyl fluoride was used to characterize the metalloproteinase nature of these proteins (Takino et al., 1995).

Third stage larva of Strongyloides stercoralis have an ability to migrate through tissue at a speed of $5-15 \mathrm{~cm}$ per hour (Greaves et al., 2013) that this process of migration was facilitated by a metalloproteinase with octase activity. This invasive property of elastase $b$ also $n$ determined by inhibition study and aut ${ }^{1}$ indicated the parasitic virulence factor may be s led by meta proteinase and could be a molec for rapeutic $p$ pose (Gomez Gallego et al., 2005 in another s dy in stor as zinc-chelator like 1, 10 enanthr he has used to prove that proteolytic a vity MMP (Hawdon et al., 1995). However th stud acentrate on the role of MMPs in transit a from free ving parasitic mode of life. In 1990 and colleag ablished a work including the study metalloproteinase from a human hookworm species Anc stoma duodenale and and zoonotic pecros $A$. caninum d they found that these two spe es could synthesis MMPs that have similar molecular we hts (68 and - kDs) and might cause tissue degradation nd ecdysis ( ptez et al., 1990). In their study, radiolabel fibrone $M$ has been degraded by both species of Ancylostom wae, which could be corroborated with the an of MMPs found in S. stercoralis larvae and Serramaruscen (Hotez et al., 1990). Healer and colleague also (Healer et al., 1991) characterized the zymogen form of MMP in larval somatic extract. However, it has been ound that uninfected rat intestinal tissue has similar kind of protein with identical molecular weight, suggesting the uptake of this metalloproteinase by the parasite.

A high pressure liquid chromatography technique has been used to purify a zinc metalloproteinase, isolated from in vitro culture fluids of Trichuris suis adults (Hill et al., 1993). Determination of isoelectric point and immunohistochemistry of MMPs has also been done in this experiment.

Analysis of tissue extracts of excretory and secretory products of Angiostrongylus cantonensis showed the activity of different form of MMPs (Lai et al., 2005b). They examined gelatinase activities from extracts of L1, L3, young and adult stages of this parasite. Five gelatinase bands (94, 86, 66, 42 and $30 \mathrm{kDs}$ ) were observed in L3 larval stages, and minimum number of bands (94 and $72 \mathrm{kDs}$ ) was seen in young and adults. All these bands of various stages showed common characteristics with MMP, cysteine and serine proteinase. Zymographic bands of L1 (105, 94 and $42 \mathrm{kDs})$ and $\mathrm{L} 3(105,66,50$ and $30 \mathrm{kDs})$ excretory and secretory products were proved to have proteolytic activity whereas adult and young excretory and secretory products had no gelatinase activity. Of these bands obtained from larval stages, 94 and $105 \mathrm{kDs}$ were gelatinase and others were metalloproteinases. In this experiment about 2000 larvae were used to detect enzyme activity while to another 
experiments 60 larvae were used to infected mice and MMPs activity was determined (Lee et al., 2004). This differentiation led to suggest that MMPs were secreted by the host not by parasite. Simultaneously, several authors provided information related with the activities of MMPs in different helminthes and MMP mediated histolysis of skin and intestinal walls (Tort et al., 1999) and degradation of ECM proteins (Petralanda et al., 1986). It has been evident that after ingestion, $A$. cantonensis larvae could invade and penetrate host stomach or intestinal wall (Lai et al., 2004). Lai and group ultimately suggested that MMPs secreted by larvae could be associated with parasite spreading and pathogenesis in host (Lai et al., 2005b).

In developing countries 740 million people are infected with hookworms (Hotez et al., 2004). In most of the cases hookworm infect took place by penetrating host's skin and after getting inside of host, larvae migrate by invading tissues of various organs (Hotez et al., 2004). Proteases have been considered as invasive arm for tissue penetration by parasitic helminthes and many experiments revealed that characterization of protease enzyme activity has been evaluated from larval, young and adult crude extract as well as excretory and secretory products of many parasites (Lai et al., 2005b).

Williamson et al. (Williamson et al., 2006) did an experiment where they found an astacin-like metalloproteinase (Ac-MTP-1) activity in excretory and secretory product of A. caninum L3 larvae. This Ac-MTP-1 has a sec similarity with zinc-metalloproteinase. L3 larval sta of A. caninum can exclusively express Ac-MTP-1and activity in culture medium indicates its ro ost tiss invasion.

In this study, activity of metalloprote ase has $b$ n provec by native and recombinant enzymes o $u^{\circ}$ om. electron microscopy, site of sy esis in secretory granules of the glandular oesor us of L3 an its course of transportation to cuticle a w wed by sem cuticle have been evaluated. Mor cently an orthologous of Ac-MTP-1 know as Ay-MTP-1 also been detected in A. ceylanicur This group of scic asts suggested a probability of ng $\mathrm{MT}^{5}$ as the target molecule for developing vaccino pro nt larval nigration through tissues. Similar 1 of $\mathrm{m}$ coprotei has been characterized from reep rber's le orm, Hemonchus contortus (Y ada et $g$ 2006). h vever, no recombinant enzymes hâ been

In a study, scientists have used the technique immunosc ving with the monoclonal antibody to synthesize a cDNA c1 from L3 larvae of Gnathostoma spinigerum. From this clone, they have identified a gene of $732 \mathrm{bp}$ encoding a metalloproteinase having 33 - 39\% similarity with MMP of Caenorhabditis elegans (Uparanukraw et al., 2001).

From above discussion it has been assumed that parasitic nematodes have the ability to modify or degrade host's extracellular matrix by secreting metalloproteinases. This process of invasive nature assists to parasites that migrate through different host tissues and causing pathogenesis.
Also, our knowledge related with characterization as well as pattern of expression of genes of these proteases in nematode parasites is not satisfactory.

In conclusion, it has been found that characterization of MMPs in parasitic nematodes have been evaluated but not with specific and sufficient information. Still we don't have enough knowledge about the different MMPs in many other of nematode parasites. Present study needs much attention towards more intense morphological and functional characterizations of gene or rene family of MMPs and all these studies relate with o sitic helminthes secreting metalloproteinas Study of g family can help to investigate more inten the pathoge city as well as to develop anti-met oprote se drug to combat against helminthic parasit

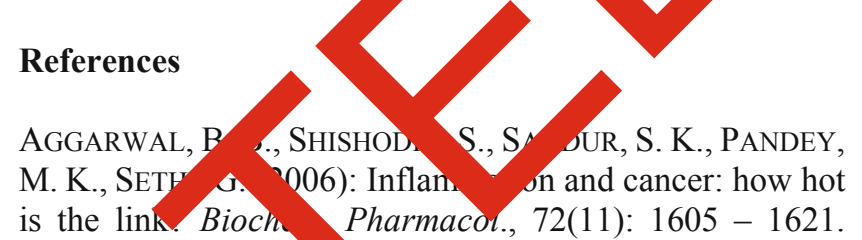
is the link. Bioch Pharmacor., 72(11): 1605 - 1621. DOI: 10 1016/j.bcp.2 06.029

Ay cRSON, R. C., ANL SON, R. C. (2000): Nematode asites of vertebrates: Their development and transmisn. 2th Editio Wallingford, UK: CABI Publishing.

B U, S. (2012 Host defenses to helminths Thome. In: RIo R. R., FI SHER, T. A., SHEARER, W. T., SCHROEDER, H., Fko J., Weyand, C. M. (Eds) Medical Clinical monology: Principles and Practice. Elsevier Health sclèns, pp. 367.

CLARK, I. M. (2001): Matrix metalloproteinase protocols. In: Young, D. A., Rowan, A. D., Clark, I. M. (Eds). Methods in molecular biology. 2th Edition. USA: Humana Press Inc. Gomez Gallego, S., Loukas, A., Slade, R. W., Neva, F. A., Varatharajalu, R., Nutman, T. B., Brindley, P. J. (2005): Identification of an astacin-like metallo-proteinase transcript from the infective larvae of Strongyloides stercoralis. Parasitol. Int., 54(2): 123 - 133. DOI: 10.1016/j.parint.2005.02.002

Greaves, D., Coggle, S., Pollard, C., Aliyu, S. H., MOORE, E. M. (2013): Strongyloides stercoralis infection. $B M J, 347:$ 4610. DOI: 10.1136/bmj.f4610

Hawdon, J. M., Jones, B. F., Perregaux, M. A., Hotez, P. J. (1995): Ancylostoma caninum: metalloprotease release coincides with activation of infective larvae in vitro. Exp. Parasitol., 80(2): 205 - 211. DOI: 10.1006/expr. 1995.1025

Healer, J., Ashall, F., Maizels, R. (1991): Characterization of proteolytic enzymes from larval and adult Nippostrongylus brasiliensis. Parasitology, 103(2): 305 - 314. DOI: $10.1017 / \mathrm{S} 0031182000059588$

HuJOVA, E. (2005): Matrix metalloproteinases: their biological functions and clinical implications. Bratisl. Lek. Listy., 106(3): 127 - 132

Hill, D. R. E., Gamble, H., RhoAds, M. L., Fetterer, R. H., UrBAn, J. (1993): Trichuris suis: A zinc metalloprotease from culture fluids of adult parasites. Exp. Parasitol., 77(2): 170 - 178. DOI: 10.1006/expr.1993.1074 
Hotez, P., Haggerty, J., Hawdon, J., Milstone, L., Gamble, H., Schad, G., Richards, F. (1990): Metalloproteases of infective Ancylostoma hookworm larvae and their possible functions in tissue invasion and ecdysis. Infect. Immun., 58(12): 3883 - 3892

Hotez, P. J., Brooker, S., Bethony, J. M., Bottazzi, M. E., LOUKaS, A., XIAO, S. (2004): Hookworm infection. $N$. Engl. J. Med., 351(8): 799 - 807. DOI: 10.1056/NEJMra 032492

LAI, S., Chen, K., Chen, H., LeE, H. (2005): Induction of matrix metalloproteinase-9 in mice during Toxocara canis larvae migration. Parasitol. Res., 95(3): 193 - 200. DOI: 10.1007/s00436-004-1271-9

LAI, S., JiAng, S., CHEN, K., LEE, H. (2005): Matrix metalloproteinases activity demonstrated in the infective stage of the nematodes, Angiostrongylus cantonensis. Parasitol. Res., 97(6): 466 - 471. DOI: 10.1007/s00436-005-1484-6 Lai, S., Twu, J., Jiang, S., Hsu, J., Chen, K., Chiaing, H., WAng, C. J., Tseng, C. K., ShyU, L. Y., LeE, H. H. (2004): Induction of matrix metalloproteinase-9 in murine eosinophilic meningitis caused by Angiostrongylus cantonensis. Ann. Trop. Med. Parasitol., 98(7): 715 - 724. DOI: $10.1179 / 000349804225021479$

Lee, H., Chou, H., Chen, K., LAI, S. (2004): Association of matrix metalloproteinase-9 in eosinophilic meningitis of BALB/c mice caused by Angiostrongylus cantonensis. Parasitol. Res., 94(5): 321 - 328. DOI: 10.1007/s00436004-1196-3

Mannello, F., Tonti, G., PAPA, S. (2005): Are ma metalloproteinases the missing link. ISJ, 2(69): $69-74$. Massova, I., Kotra, L. P., Fridman, R., M UERY, S (1998): Matrix metalloproteinases: struc es, e lution, and diversification. FASEB. J., 12(12):

MCDOnnell, S., Morgan, M., Ly

matrix metalloproteinases in norp and di processes. Biochem. Soc. Tran., 27(4): 73740

NAGASE, H., VISSE, R., My AY, (2006): Str yre and function of matrix metalloproteinaso nd TIMPs. Cardiovas. Res., 69(3): 562 573. DOI: 10. 16/j.cardiores.20 05.12 .002

PARKS, W. C., S APIRO, S (2000): Matrix metalloproteinases in lung b ag resp. Re 2(1): 10 - 19. DOI: $10.1186 / \mathrm{rr}^{20}$

PETRAI AA, YARZ YL PIESSENS, W. F. (1986): Stud on a fil al antige 1 th collagenase activity. Mol. Bioc n. $\mathrm{Pg}$ (1): 51 - 59. DOI: 10.1016/01666851(8 O $05-4$

SAlter, J. Choe, Y., Albrecht, H., Franklin, C., Lim, K.-C., Craik S. S., McKerrow, J. H. (2002): Cercarial elastase is encoued by a functionally conserved gene family across multiple species of schistosomes. J. Biol. Chem., 277(27): 24618 - 24624. DOI: 10.1074/jbc.M2023 64200
SHAPIRO, S. D. (1998): Matrix metalloproteinase degradation of extracellular matrix: biological consequences. Curr. Opin. Cell. Biol., 10(5): 602 - 608. DOI: 10.1016/S09550674(98)80035-5

Takino, T., Sato, H., Shinagawa, A., Seiki, M. (1995): Identification of the second membrane-type matrix metalloproteinase (MT-MMP-2) gene from a human placenta cDNA library MT-MMPs form a unique membrane-type subclass in the MMP family. J. Biol. Chem., 270(39): 23013 - 23020. DOI: 10.1074/jbc.270.39.22012

Tort, J., Brindley, P. J., KNOX, P WOL K. H., DALTON, J. P. (1999): Proteinases associated es of parasitic helminths. Adv. Parasitol., $161-266$ DOI: 10.1016/S0065-308X(08)6024?

UGalde, A. P., ORdóÑEZ,

X. S., LÓPEZ-OTÍN, C. 10): M Aloprou and the degradome. In: Matr Meto proteinase Protocols. Springer, pp. $3-29$

UpARANUKRAW T., MORA TE, HARnNOI, T., DANTRAKOO A. 2001): Mola cloning of a gene encoding marrix me aproteinase-rike protein from Gnathostoma cninigerum. asitol. Res., 87(9): 751 - 757. DOI $0.100 / / \mathrm{s} 004360100 \%$

VIs E, R., NAGASE, H. (2003): Matrix metalloproteinases an tissue inhibit of metalloproteinases structure, function and biochem try. Circ. Res., 92(8): 827 - 839. DOI: 10.1 01.RES J00070112.80711.3D

WANG, A LEN, R., Ding, X., GOELlner, M., MAIER, Boer, J. M., Baum, T. J., Hussey, R. S., Davis, E. (200. Signal peptide-selection of cDNA cloned directly from the oesophageal gland cells of the soybean cyst nematode Heterodera glycines. Mol. Plant. Microbe. Interct., 14(4): 536 - 544. DOI: 10.1094/MPMI.2001.14.4.536 Williamson, A. L., Lustigman, S., OKsov, Y., Deumic, V., Plieskatt, J., Mendez, S., Zhan, B., Bottazzi, M. E., Hotez, P. J., LoukAS, A. (2006): Ancylostoma caninum MTP-1, an astacin-like metalloprotease secreted by infective hookworm larvae, is involved in tissue migration. Infect. Immun., 74(2): 961 - 967. DOI: 10.1128/IAI.74.2. 961-967.2006

YAtsuda, A. P., BAKKer, N., KRijgsveld, J., KnOX, D. P., HECK, A. J., DE VRIES, E. (2006): Identification of secreted cysteine proteases from the parasitic nematode Haemonchus contortus detected by biotinylated inhibitors. Infect. Immun., 74(3): 1989 - 1993. DOI: 10.1128/IAI.74.3.19891993.2006

YoshizaKi, T., SATO, H., FuruKaWA, M. (2002): Recent advances in the regulation of matrix metalloproteinase 2 activation: From basic research to clinical implication (Review). Oncol. Rep., 9(3): 607 - 611. DOI: 10.3892/ or.9.3.607 